\title{
Research Bulletin
}

\section{DG Research, No. 5, December 2006}

\section{Editorial}

By Lucas Papademos, Vice-President, ECB.

Solid economic research is indispensable for the effective formulation and implementation of central bank policy. Since its inception, the ECB has always recognised the crucial role of research and has devoted considerable efforts to deepening its understanding of the environment in which it operates. This commitment to research is clearly evident, for example, in the ECB's publications, particularly the Working Paper and Occasional Paper series. In order to maintain high standards, central bank researchers need to pursue an active dialogue with the broader research community. The dissemination and communication of research findings is an essential element of this process. With the publication of this issue of the Research Bulletin, the ECB is seeking to make the research work by its economists known to a wider audience of experts and nonspecialists alike. The articles, which reflect the views of the individual authors and do not necessarily represent those of the $E C B$, aim to present the latest research in an easily accessible format.

The first article in this issue provides an overview of research on the role of communication in monetary policy-making, focusing on work carried out within the ECB. Communication between central banks and financial markets and the general public is increasingly acknowledged as a key element. It is therefore not surprising that in recent years the issue of central bank communication has attracted the attention of economists both within and outside central banks. The second article provides a review of the Real-Time DataBase project which has been undertaken by the ECB in collaboration with National Central Banks and the Euro Area Business Cycle Network. The database is an important resource as it helps economists to identify the extent to which the basic time series that are used as inputs into monetary policy are subject to revisions. In the future, it will also enable users to analyse how monetary policy was conducted in real time. The third article focuses on the conduct of monetary policy in a "corridor system" like the one used by the ECB to implement its interest rate policy. One result is that central bank collateral policy plays an important role in determining the optimal size of the corridor and the behaviour of the short-term money market rate.

\section{Table of contents}

\section{Editorial}

Central bank communication, by M. Ehrmann

A Real-Time DataBase for the euro area, by M. Ciccarelli, G. Coenen and J. Henry

Implementing monetary policy using a corridor system, by A. Berentsen and C. Monnet

Box: The Wim Duisenberg Research Fellowship Programme

\section{References}

Selected recent journal publications by ECB Staff

The opinions expressed in this publication are those of the authors and do not necessarily reflect those of the European Central Bank. Editors: Günter Coenen, Carsten Detken, Gabriel Fagan, Philipp Hartmann. Responsible editor for this edition: Günter Coenen with the support of Kai Christoffel.

Contact for general information about the Research Bulletin and subscription to the Research Bulletin: ECB-ResearchBulletin@ecb.int. Assistance to editors: Petra Angel

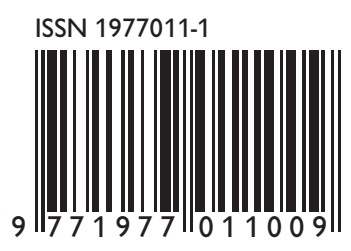


Communication is an important part of the process of conducting monetary policy. Although central banks only have direct control over a single interest rate, usually the overnight rate, they may also attempt to influence interest rates at all maturities. Effective communication - as much as credible policy actions - is of fundamental importance for achieving these objectives. The recent changes seen in the role and practice of central bank communication have spurred a rapidly growing academic literature on this topic, on which this article reports. It shows that central bank communication is an important policy tool, with substantial effects on financial markets, and the potential to enhance the efficiency of monetary policy-making.

\begin{abstract}
Along with, and partially due to, the recent trend towards central bank independence around the globe, transparency is nowadays considered best practice in central banking. One trigger for increased transparency has likely been the obligation of independent central banks to be accountable. At the same time, however, academics and central banks have become increasingly aware that transparency can enhance the effectiveness of policy. Communication is vital for both accountability and transparency. ${ }^{1}$ Accordingly, central banks are now placing greater emphasis on communicating directly with the public than in the past. This increased importance has had an effect on the various facets of communication, such as the announcement and clarification (and often quantification) of a central bank's objectives, the announcement and explanation of monetary policy decisions and the communication of the central bank's current assessment of the economic situation and its outlook.
\end{abstract}

\section{The announcement of a central bank's objective}

If a central bank is granted independence from its government, it must be given a clearly defined mandate. This is generally done by defining central bank objectives, often in a quantified fashion. But even if central banks are not given a quantitative objective, they often decide to provide their own quantification, or are required to do so. The potential effects of such a clarification and quantification are substantial: they make an independent central bank more (easily) accountable, since its actions can be assessed by cross-checking actual economic outcomes with those mandated; furthermore, the announcement of an objective, and in particular its quantification, provides a yardstick for the expectations of economic agents. For instance, knowing that a central bank will ensure price stability, and having a quantitative notion of what this means, agents can form expectations about future inflation outcomes accordingly (provided the announced objective is credible). While this effect can, in principle, facilitate the conduct of monetary policy (after all, it is much easier to maintain price stability once inflation expectations are well anchored), it remains an empirical issue whether the potential gains have indeed materialised. A look at the corresponding empirical evidence can shed light on this issue.

There is a clear consensus that increased transparency about central banks' strategies, and in particular the announcement of an explicit inflation objective, has fostered central bank credibility as well as the predictability of the path of monetary policy. Although its contribution cannot be separated from that of ongoing communication on the central bank's assessment of the current policy stance, the recent trend towards more transparent central banking practices has certainly played a considerable part in improving the short-term predictability of policy decisions by many central banks over recent decades (as measured by the accuracy of market expectations at the time the decision-making bodies meet; BIS 2004, pp. 73-80).

Moving beyond this short-term predictability, Levin et al. (2004) find that inflation persistence is considerably lower in countries where central banks have adopted an explicit inflation objective. They also show that, in such countries, private sector inflation expectations are not correlated with lagged inflation, which thus indicates that inflation expectations are better anchored. This evidence has been corroborated in a recent paper by Gürkaynak et al. (2006), which shows that in Sweden and the United Kingdom, i.e. two inflationtargeting countries, long-term inflation expectations as derived from index-linked bonds are less responsive to macroeconomic data releases and monetary policy announcements than inflation expectations in the United States, where no explicit inflation objective has been announced.

However, the fact that the announcement of a central bank's objective has an effect on inflation expectations need not automatically imply that there will be an effect on the ultimate objective. Again, this question needs to

1 While communication and transparency are closely related in many ways, they are not identical: although communication can be a means to achieve transparency, not all communication necessarily contributes to transparency. 
be settled empirically. Diron and Mojon (2005) show that the inflation objectives announced by central banks are good forecasters of actual inflation, outperforming model-based and published forecasts; a finding that suggests that inflation objectives tend to be achieved and should therefore be credible. A recent paper by Fatas et al. (2006) makes the link between having (and meeting) a quantified objective and inflation outcomes. Looking at more than 40 countries over 40 years, they find that inflation is lower if there is a numerical objective and even more so, if this objective is actually achieved. According to their results, it is primarily the quantification of the objective that matters, more than its exact form.

In sum, the empirical evidence available suggests strongly that the announcement of a central bank's objective is beneficial, since it eases the conduct of monetary policy through its effect on agents' expectations and helps to achieve sound macroeconomic outcomes.

\section{The announcement of policy decisions}

It is common practice nowadays among central banks to inform the public about monetary policy decisions as soon as the decision has been taken. There is substantial evidence that this practice improves the markets' understanding of monetary policy considerably, for instance for the Federal Reserve System, which makes such same-day announcements since February 1994. Previously, markets had had to infer the intended federal funds rate from the type and size of the open market operations by the Federal Reserve until the decision was published after the subsequent Federal Open Market Committee (FOMC) meeting. Lange et al. (2003), Poole and Rasche (2003) and Demiralp (2001) observe that the change in communication practices has enabled markets to improve their forecasts of monetary policy decisions. Furthermore, Demiralp and Jorda (2002) provide evidence that, by announcing changes to the intended federal funds rate in real time, it has been possible to move the federal funds rate with a smaller volume of open market operations, which indicates that the announcement of policy decisions helps to increase transparency and can therefore make policy implementation more efficient.

\section{The communication of the current assessment of the economic situation and the monetary policy stance}

By announcing an objective, and possibly releasing information on its monetary policy strategy, on the models used and on the variables considered in the economic analysis, a central bank aims to help the public better understand its broader framework and the way in which it reacts to different circumstances and contingencies. However, even if the broader framework is generally well understood, the central bank must still communicate regularly its assessment of the current economic situation and the monetary policy stance, since it will be impossible to communicate ex ante all contingencies in such a way that the public can always deduce perfectly the central bank's assessment, just by interpreting the incoming macroeconomic data. Such regular communication is important for financial market participants, for instance in order to fine-tune their market positions with respect to upcoming decisions. A clear indication about the attention such communication receives is the extent of reporting on it by financial newswire services.

Communication that explains the background to a given policy decision, or that provides information about any future decisions, is considered to be important by the market.

As argued above, central banks have recently been highly predictable in their actions in the sense that, by the time of the meeting, decisions have generally been very well anticipated by markets. Accordingly, it is not surprising

\section{Table I: Market effects of different types of communication by the Federal Reserve}

\begin{tabular}{|c|c|c|c|c|}
\hline & \multicolumn{2}{|c|}{$\begin{array}{c}\text { Average absolute effect } \\
\text { per event }\end{array}$} & \multicolumn{2}{|c|}{$\begin{array}{l}\text { Cumulative absolute effect } \\
\text { since } 2001\end{array}$} \\
\hline & $\begin{array}{l}\text { Eurodollar } \\
\text { futures rate }\end{array}$ & $\begin{array}{r}2 \text {-year } \\
\text { treasury yield }\end{array}$ & $\begin{array}{l}\text { Eurodollar } \\
\text { futures rate }\end{array}$ & $\begin{array}{r}2 \text {-year } \\
\text { treasury yield }\end{array}$ \\
\hline Statements & 4.5 & 5.6 & 103 & 140 \\
\hline Testimonies & 6.7 & 6.8 & 28 & 33 \\
\hline Minutes & 1.9 & 2.5 & 41 & 71 \\
\hline Old release & 1.7 & 2.3 & 21 & 50 \\
\hline Expedited release & 3.4 & 3.8 & 20 & 20 \\
\hline Speeches & 0.3 & 0.5 & 75 & 119 \\
\hline
\end{tabular}

Source: Reinhart and Sack (2006).

Note: The table shows the absolute effects in basis points of different types of communication in a time window of 15 minutes before the event and until one hour after. "Statements" denote the statements announcing monetary policy decisions, which contain the current decision as well as a forward-looking element (see box). "Expedited release" of the minutes: since December 2004. 


\section{Box: Qualitative guidance about future policy decisions}

There are stark differences in the current practices of central banks regarding the provision of forward guidance on the future path of interest rates, ranging from quantitative announcements of the interest rate path used for the central banks own inflation forecasts (as practiced by the Reserve Bank of New Zealand and Norges Bank) to no explicit forward guidance. An intermediate position is taken by the Federal Reserve, which has used different forms of qualitative guidance, through explicit statements on the bias or balance of risks, indicating the likely future direction of interest rates. These statements have been shown to strongly affect financial markets (see Table 1). At the same time, they have clearly changed the way markets react to the Federal Reserve's communication in general (Ehrmann and Fratzscher 2005). The strong market reaction to the statements implies that markets often start pricing in the interest rate decision of the next meeting on the day of the preceding meeting. As the statements have generally been consistent with future policy actions, markets have been well advised to react accordingly. Surprisingly, however, the immediate release of the statements ${ }^{1}$ since 1999 has not improved the accuracy of the markets' anticipation of FOMC decisions just prior to the respective FOMC meeting. The main difference is that without statements, markets generally started pricing in future interest rate decisions later in the period between meetings, leaving a larger role for other communication such as testimonies and speeches by FOMC members.

Chart 1 illustrates the differences in the adjustment of the three-month t-bill rate around two consecutive FOMC meeting dates: one prior to 1999 , one post-1999. Both cases are very similar in that no change occurred at the first of the two FOMC meetings (marked as day 0 on the horizontal axis) and a rise in the federal funds target rate by 25 basis points took place at the subsequent meetings (marked as day 30). Furthermore, in both cases, the FOMC had actually adopted a tightening bias at the previous meeting. The main difference between the meetings lies in the communication of this bias, which had been released immediately in one case, but only after the subsequent meeting in the other case.

In both instances, the policy decision to change interest rates was well predicted by the market: interest rates had already increased substantially by the time the FOMC met. However, it is apparent that this anticipation of the decision was achieved through very different mechanisms in the two cases. Where a tightening bias was released at day 0 , markets already priced in most of the interest rate rise of the next meeting within one day. By contrast, in the case without a released statement, interest rates adjusted much later. Interestingly, interest rates started anticipating the interest rate move on the day of Chairman Greenspan's testimony before the US Senate on 26 February 1997 (day 11 in the chart).

Although the example in the chart certainly shows an exceptionally strong case, it serves to illustrate the potential effects of the statements. Statistical testing confirms the impression gained from the chart: markets' anticipation of monetary policy decisions has not ultimately been affected by the immediate release of the statements, but markets have arrived at their expectations in different ways. Nowadays, they extract information from the statements, whereas before they relied more on other types of Federal Reserve communication in between meetings, such as speeches and testimonies by FOMC members. 
Table 2: Market reaction to communication by committee members (1999-2004)

\begin{tabular}{rccc} 
& Federal Reserve & Bank of England & European Central Bank \\
\cline { 2 - 4 } 3-month interest rates & $0.97^{* * *}$ & $0.46^{* * *}$ & $2.05^{* * *}$ \\
6-month interest rates & 0.46 & $0.80^{* * *}$ & $1.57^{* * *}$ \\
1-year interest rates & $0.88^{* *}$ & $0.95^{* *}$ & $2.47^{* * *}$ \\
2-year interest rates & $1.01^{*}$ & 0.13 & $2.48^{* * *}$ \\
5-year interest rates & $1.14^{*}$ & 0.15 & $1.96^{* * *}$ \\
10-year interest rates & 0.76 & -0.21 & 0.61 \\
20-year interest rates & 0.64 & 0.02 & 0.44
\end{tabular}

Source: Ehrmann and Fratzscher (2006).

Note: The table shows the response of interest rates in basis points to speeches and interviews given by committee members of the different central banks, containing some non-neutral reference to monetary policy inclinations. "Hawkish" statements are coded as +1 , "dovish" statements as -1 . Based on daily data. $* / * * * * *$ denotes significance at the $90 \% / 95 \% / 99 \%$ level.

that markets react predominantly not to the announcement of the decision, but to the communication on the day of the meeting, i.e. the explanation of the reasons underlying the decision and any forward-looking component. Gürkaynak et al. (2005) for the Federal Reserve and Brand et al. (2006) for the ECB find that financial markets respond mainly to two components of the communication on meeting days: possible surprise components of the decision and the forward-looking component of the communication. Importantly, the latter is the dominant market mover, particularly for longer-term maturities in the yield curve.

Looking at the cases of the Federal Reserve System and the Bank of England, there are also very strong market reactions to the minutes, which have increased considerably with expedited release practices, in which the minutes are now made public prior to the subsequent meeting. As shown in Table 1, this has approximately doubled the market reaction to their release in the United States. A similar finding holds for the Bank of England. ${ }^{2}$

However, central bank officials do not only communicate on meeting days; in the inter-meeting period, they also deliver speeches or give interviews, which often contain elements of the current assessment of the economic situation or the monetary policy stance. Table 1 shows that, in the case of the Federal Reserve, speeches by officials generally affect financial markets less than the statements on meeting days, testimonies or the minutes. However, due to their larger number, their cumulative effect over time is substantial, second only to that of the statements on meeting days.

Taking a closer look at such communication activities (see Table 2) reveals that speeches and interviews have the potential to affect interest rates throughout almost the entire maturity spectrum. If they are perceived by the markets as including statements suggesting a policy tightening inclination they lead to increasing rates, and if perceived as suggesting an easing inclination to lower rates. Furthermore, market-moving effects are found for all central banks, and the effects can be sizable - in the case of the ECB, each non-neutral statement moves interest rates on average by $1.5-2.5$ basis points.

Overall, the evidence supports the view that central bank communication is an important policy tool. It has a substantial effect on financial markets and the potential to enhance the efficiency of monetary policy-making. Although this notion is now well understood, research in this field is still developing, and rapidly so. Due to the availability of high frequency data, much of the empirical research has focused on the effects of communication on the financial markets. Although important, financial markets are not the only addressee of central bank communication. A central bank needs to reach out to a wider audience as well, since it is the general public whose inflation expectations eventually feed into the actual evolution of inflation - for example, through corresponding wage claims and savings, investment and consumption decisions - and thus determine whether a central bank is able to achieve its policy objectives. How effectively a central bank communicates with the general public, and how this communication is perceived should be an important focus of future research. 


\section{A Real-Time DataBase for the euro area}

By Matteo Ciccarelli, Günter Coenen and Jérôme Henry, ECB

The euro area Real-Time DataBase is a project co-ordinated by the Euro Area Business Cycle Network, in co-operation with a number of European central banks, including the ECB. The first outcome of this project, produced jointly by ECB's Directorates General Research and Statistics, is a database comprising selected macroeconomic time series for the euro area, as reported in each issue of the ECB's Monthly Bulletin. Following a brief summary of the various steps involved, this article illustrates the relevance of building such a database by providing statistics on the revisions affecting some key macroeconomic variables. It also demonstrates the potential consequences of the implied degree of data uncertainty for monetary policy-making, and indicates how the project is expected to develop.

\section{The Real-Time DataBase project}

The Real-Time DataBase (RTDB) is a project coordinated by the Euro Area Business Cycle Network $(\mathrm{EABCN})$, which comprises a large number of European central banks, including the ECB. The purpose of the project is to construct a real-time database for both the euro area as a whole and the individual European countries to establish facts and stimulate research on the broad topic of real-time analysis.

After a comprehensive feasibility study and a survey of available archives were carried out two years ago by the EABCN and its supporting institutions, a two-stage project was devised: first, a euro area-wide RTDB should be constructed at the ECB, and second country-level RTDBs should be compiled by the participating national central banks.
The first step was undertaken jointly by the ECB's Directorates General Research and Statistics. The resulting "pilot" database comprises archives of time series of a large number of euro area macroeconomic variables, as regularly reported in the ECB's Monthly Bulletin. ${ }^{1}$ It therefore contains the data that were available at the time of monetary policy decisions, with the cut-off date always being one day before the corresponding Governing Council meeting. The Monthly Bulletin RTDB thereby comprises, from 1999 onwards, monthly snapshots of euro area macroeconomic data with known release dates - the vintages - of more than 200 variables, covering a time span of up to 35 years (even though most of the series are only available since the late 1980 s or early 1990s).

1 For a detailed description of the Monthly Bulletin RTDB, see Giannone Henry, Lalik and Modugno (2006).

\section{Table I: Euro area data revisions}

\begin{tabular}{|c|c|c|c|c|c|}
\hline Revision after month & 4 & 6 & 8 & 12 & 16 \\
\hline Real GDPa & Quarterly gro & & & & \\
\hline $\begin{array}{l}\text { mean absolute error } \\
\text { minimum } \\
\text { maximum }\end{array}$ & $\begin{array}{r}0.10 \\
-0.16 \\
0.28 \\
\text { Annual grow }\end{array}$ & $\begin{array}{r}0.09 \\
-0.20 \\
0.23\end{array}$ & $\begin{array}{r}0.07 \\
-0.16 \\
0.17\end{array}$ & $\begin{array}{r}0.05 \\
-0.13 \\
0.10\end{array}$ & $\begin{array}{r}0.04 \\
-0.11 \\
0.05\end{array}$ \\
\hline $\begin{array}{l}\text { mean absolute error } \\
\text { minimum } \\
\text { maximum }\end{array}$ & $\begin{array}{r}0.22 \\
-0.60 \\
0.25\end{array}$ & $\begin{array}{r}0.20 \\
-0.57 \\
0.24\end{array}$ & $\begin{array}{r}0.17 \\
-0.52 \\
0.21\end{array}$ & $\begin{array}{r}0.14 \\
-0.36 \\
0.10\end{array}$ & $\begin{array}{r}0.10 \\
-0.31 \\
0.10\end{array}$ \\
\hline GDP deflator ${ }^{\mathrm{a}}$ & Quarterly gro & & & & \\
\hline $\begin{array}{l}\text { mean absolute error } \\
\text { minimum } \\
\text { maximum }\end{array}$ & $\begin{array}{r}0.12 \\
-0.25 \\
-0.01 \\
\text { Annual grow }\end{array}$ & $\begin{array}{r}0.10 \\
-0.22 \\
0.08\end{array}$ & $\begin{array}{r}0.08 \\
-0.22 \\
0.02\end{array}$ & $\begin{array}{r}0.09 \\
-0.27 \\
0.12\end{array}$ & $\begin{array}{r}0.09 \\
-0.29 \\
0.14\end{array}$ \\
\hline $\begin{array}{l}\text { mean absolute error } \\
\text { minimum } \\
\text { maximum }\end{array}$ & $\begin{array}{r}0.25 \\
-0.35 \\
0.15\end{array}$ & $\begin{array}{r}0.20 \\
-0.36 \\
0.08\end{array}$ & $\begin{array}{r}0.17 \\
-0.42 \\
0.11\end{array}$ & $\begin{array}{r}0.15 \\
-0.33 \\
0.10\end{array}$ & $\begin{array}{r}0.13 \\
-0.44 \\
0.12\end{array}$ \\
\hline HICP & Annual grow & & & & \\
\hline $\begin{array}{l}\text { mean absolute error } \\
\text { minimum } \\
\text { maximum }\end{array}$ & $\begin{array}{r}0.07 \\
-0.10 \\
0.38\end{array}$ & $\begin{array}{r}0.07 \\
-0.10 \\
0.38\end{array}$ & $\begin{array}{r}0.05 \\
-0.10 \\
0.38\end{array}$ & $\begin{array}{r}0.04 \\
-0.01 \\
0.38\end{array}$ & $\begin{array}{l}0.02 \\
0.00 \\
0.19\end{array}$ \\
\hline
\end{tabular}

Source: Euro area RTDB October 1999 - August 2005.

${ }^{a}$ Seasonally adjusted data. 
In October 2005, following extensive testing and reformatting, an initial set of 38 of the most important nominal, real, financial and monetary data was made available in Excel format to members of the EABCN on its website (www.eabcn.org). The data are provided according to two dimensions: the month in which they were stored for publication in the Monthly Bulletin and the observation to which they refer. For each series, a given observation may then take a different value for each month of the sample collected, depending, among other things, on data revisions.

The ultimate long-term goals of the RTDB project are to construct and disseminate the data at both the euro area and country levels. In terms of indicator coverage, it will be one of the most comprehensive real-time databases available in Europe.

\section{Quantification of data revisions}

To illustrate the possible extent of data revisions, three variables of particular interest are reviewed below: real GDP, the GDP deflator and the Harmonised Index of Consumer Prices (HICP). In this context, a revision is defined as the difference between a "final" figure identified as the data for a given quarter (or month) reported 24 months after the end of that quarter (month) ${ }^{2}$ - and an intermediate figure - the data for the same quarter (month) reported $h$ months after the end of that quarter (month).
Table 1 provides summary statistics for the revisions of the selected variables, as obtained from the euro area RTDB. The mean absolute error characterises the overall degree of uncertainty associated with data revisions (by indicating the average absolute size of revisions regardless of their sign). The minimum and maximum give an indication of the potential magnitude of downward and upward revisions. For real GDP and the GDP deflator we also report the annual growth rates to give an idea of the cumulated size of the revisions.

The summary statistics show that the cumulated revisions of real GDP data can be sizeable. For example, the difference between real GDP data available after 24 months and the data reported after four, or even eight months sometimes exceeded 0.5 percentage point. A broadly similar picture emerges for the GDP deflator, although the maximum upward and downward revisions are slightly smaller. By contrast, consumer price data are typically not revised; the only exceptions are apparently due to corrections of reporting errors or changes in methodology, including the weighting scheme.

The potential consequences that data revisions may have for monetary policy-making are illustrated in the following box.

2 In practice, data can be revised at any moment in time due, for example, to major methodological changes that often lead to the reconstruction of the whole history for some series. However, it can reasonably be assumed that the data available two years after the initial recording are close to some concept of "final" data, at least as far as their use for projections and for monetary policy analysis is concerned.

\section{Box: Implications of data revisions for monetary policy-making}

To visualise the potential implications of data revisions for monetary policy-making, Coenen, Levin and Wieland (2005) use an estimated small-scale macroeconomic model of the euro area, which is augmented with a calibrated specification of the output revision process. According to this specification, the "final" measure of current-quarter output is published three quarters after the initial release and assumed to represent the true value of output.

Chart 1: Output

$$
\begin{aligned}
& \text { _... with measurement error } \\
& \ldots \text { perceived value } \\
& \text {. without measurement error }
\end{aligned}
$$

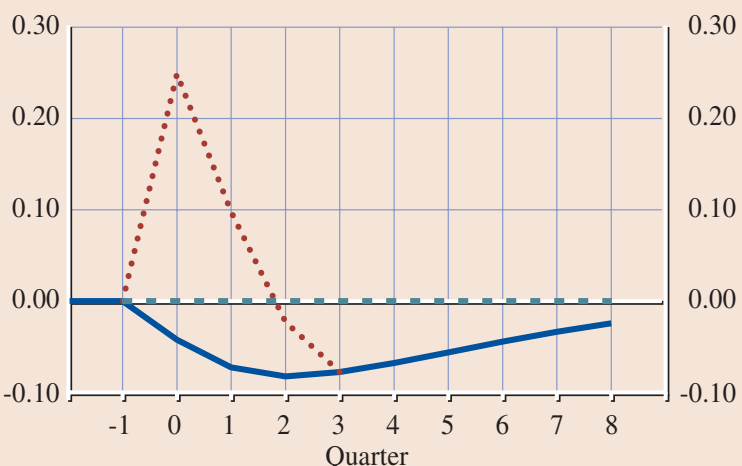

Chart 2: Short-term nominal interest rate

$$
\begin{aligned}
& \text { with measurement error } \\
& \ldots . . \quad \text { predictions at } \mathrm{t}=0,1,2 \\
& \ldots \text { without measurement error }
\end{aligned}
$$

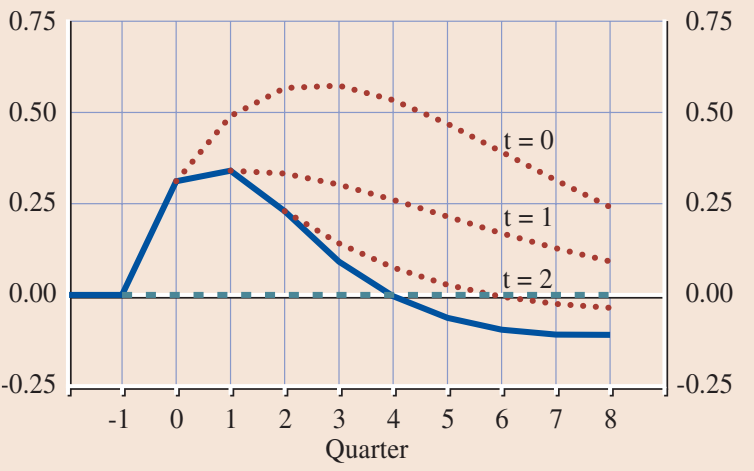


The monetary authority optimally sets the short-term nominal interest rate to minimise a weighted average of inflation volatility and output gap volatility, subject to a small penalty on nominal interest rate movements. Furthermore, the monetary authority and private agents weigh the available information optimally to make inferences about the uncertain value of output. Implicitly, it is assumed that the initial estimate of output, which the statistical agency constructed from disaggregated data, can be improved upon by synthesising aggregate data on a broad range of real, monetary and financial variables within a fully specified macroeconomic model.

The above charts summarise the results of an experiment in which the value of output reported at time zero contains a measurement error of nearly a full percentage point. Under optimal filtering, however, this observation is largely down-weighted, and hence the perceived value of output at time zero is only $0.25 \%$ above baseline. Nevertheless, the optimal policy prescribes an immediate 25 basis point rise in the short-term nominal interest rate and private agents predict short-term rates at time zero to rise further before returning gradually to baseline. With the resulting rise in the implied long-term real rate at time zero, true output actually declines below baseline. Later, when the measurement error is corrected by subsequent revisions, the monetary authority reduces rates a bit below baseline to nudge the economy back in the right direction. Consequently, private agents gradually revise their predictions of future short-term interest rates downwards a number of times. Thus, while true output never deviates very far from baseline, the output mis-measurement does cause a noticeable fluctuation in current and expected short-term interest rates.

\section{The way forward}

Up-to-date information on recent developments in real-time research was exchanged at the sixth EABCN workshop, hosted by the Nationale Bank van België/Banque Nationale de Belgique on 13 and 14 June 2005. This workshop confirmed the need to also initiate a comprehensive collection of real time data at the country level. Consequently, a number of central banks have started to construct country-level RTDBs, which should be ready by autumn 2007. In the meantime, an expert group has been formed to investigate the technical aspects related to data storage and dissemination as well as updating procedures, all of which are non-trivial issues, given the volume and complexity of an evolving multi-country realtime database.

The ultimate goal of the RTDB project is to stimulate applied research on real-time data, given that the decisions of both private agents and policy-makers have to be taken in real time. In this respect, future research must not only establish stylised facts on data revisions in Europe (to be compared with findings for the United States), but also assess the consequences of using real-time data for forecast evaluations, explore the empirical robustness of available macroeconomic evidence and analyse the implications of data uncertainty for monetary policy-making.

\section{Implementing monetary policy using a corridor system}

By Aleksander Berentsen, University of Basel, and Cyril Monnet, ECB

For most central banks, the short-term interest rate in the interbank market (the money market rate) is the operational target. ${ }^{1}$ They use two main instruments to influence the money market rate: standing facilities and/ or open market operations. ${ }^{2}$ For instance, the European Central Bank (ECB) offers a borrowing facility and a deposit facility, and conducts weekly liquidity auctions. Through its borrowing facility, the ECB stands ready to lend cash overnight against proper collateral at a fixed rate - the marginal lending facility rate, or the lending rate for short. With the ECB's deposit facility, banks with excess cash can make overnight deposits and earn the deposit facility rate or deposit rate. Through its weekly liquidity auctions, banks can obtain cash (against proper collateral) if they bid a rate which is sufficiently high (relative to other bids) and higher than the minimum bid rate set by the ECB. The minimum bid rate can be considered as the ECB's policy target rate for the shortterm money market rate.

The difference between the lending rate and the deposit rate is called the interest rate corridor. Since

1 This short article is not concerned with the question of why central banks target the short-term money market interest rate. For a discussion of other operational targets, see Bindseil (2004), for example.

2 Reserve requirements are sometimes considered to be a third instrument. 
banks can borrow overnight at the lending rate, they will never borrow in the money market at a higher rate. Therefore, the lending rate puts a "ceiling" on the money market rate. Similarly, banks will never lend money at a rate below the deposit rate, which therefore provides a "floor" for the money market rate. As a consequence, the money market rate always lies within a corridor.

The ECB implements its monetary policy by changing the lending, deposit and minimum bid rates. For example, when the ECB tightens its monetary policy, it increases these rates by the same amount. Chart 1 shows the ECB's corridor system together with the relevant money market rates: the euro overnight index average (EONIA), a weighted average of the rates for overnight unsecured transactions on the money market, and the Eurepo, the reference rate for secured transactions. ${ }^{3}$

Other central banks, such as those in Australia, Canada, New Zealand and the United Kingdom, use a similar framework to implement monetary policy.

Although central banks have now gained some experience with corridor systems, implementing monetary policy via a corridor system raises several questions. First, why do central banks choose distinct lending and deposit rates? Second, why do central banks choose different corridors? For example, the corridor of the ECB is 200 basis points, while the one operated by the Reserve Bank of New Zealand is only 50 basis points. Finally, what is the mechanism through which such a framework affects the level of the short-term money market rate and, in

Chart 1: EONIA - Euro OverNight Index Average and Eurepo - reference rate for the Euro General Collateral repo market
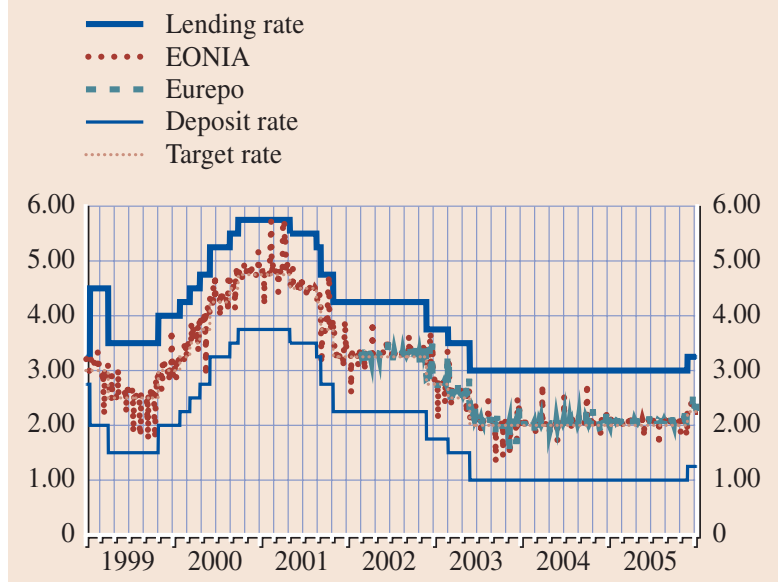

Source: European Banking Federation and ECB particular, why do money market rates tend to lie in the middle of the corridor?

The last question was studied by Poole $(1968)^{4}$, who considered a partial equilibrium model where a bank faces stochastic shocks to its reserves. Assume that the bank has a zero average reserve requirement. In addition, assume that the end-of-day liquidity shock is equally likely to be a positive amount $x$ (in which case the bank will use the deposit facility) or a negative amount $-x$ (in which case the bank will access the lending facility). In this setting, Poole shows that a simple arbitrage argument for the money market yields a money market rate that is exactly the average of the deposit and lending rates, and hence lies in the middle of the corridor. The fact that in reality the money market rate does not always lie exactly in the middle of the corridor is simply due to some "noise" in exogenous factors determining the overall liquidity demand that are difficult to forecast. ${ }^{5}$

Obviously, Poole's argument is a little more intricate; however, the simplified interpretation given above can be carried through into a more complex model. Still, there are several shortcomings in this analysis. First, the model is a partial equilibrium model with only one bank, so no lending or borrowing can take place in the interbank market. Second, all loans are uncollateralised, whereas in reality central banks always require collateral. Third, the question of how macroeconomic aspects such as inflation affect the operation of a corridor system is omitted. Furthermore, the model cannot answer normative questions. For instance, it cannot explain why it is optimal for central banks to choose a positive interest rate corridor or why corridors should differ among central banks.

In his recent book on monetary policy implementation, Bindseil (2004) suggests that the interbank market only has a role in allocating liquidity insofar as the interest rate corridor is positive. Indeed, if the deposit rate equalled the lending rate, banks would have no incentive to trade with one another and so no (short-term) market trading would take place. However, some open questions remain. Bindseil does not answer the question of why the cost of having no interbank market always outweighs the benefits of implementing a zero band corridor. Such a corridor would greatly simplify the provision of liquidity: with a zero band, no open market operations would be needed, as banks would access the borrowing facility to finance a negative liquidity shock, and banks' liquidity

3 There are many studies on the behaviour of the EONIA and on the ECB's liquidity auctions, for instance Hartmann, Manna and Manzanares (2001), Nyborg, Bindseil and Strebulaev (2002) and Ewerhart, Cassola, Ejerskov and Valla (2004).

4 Poole's model has been extended by Gaspar, Perez-Quiros and RodriguezMendizabal (2004). See also Whitesell (2006).

5 This includes, for instance, government tax receipts. 
management may be significantly simplified. Moreover, the peer monitoring argument does not explain why corridors differ in size across countries.

The lack of theoretical studies on corridor systems and the limitations of Poole's model indicate that there is much room for improvement in our understanding of the corridor system. As a first step, we present a dynamic general equilibrium model that provides answers to the above questions. The model consists of households, banks and a welfare-optimising central bank. Households trade and hold accounts with banks. There is a zero reserve requirement and, as in Poole's model, households are subject to idiosyncratic trading shocks which generate random liquidity needs for them and for their banks. Banks can partially insure against these shocks in a secured money market. To provide further insurance, the central bank operates a standing facility where agents can borrow or deposit money at the specified rates. There is also no limit on the size of a loan that a bank can obtain provided that the loan is fully collateralised.

The following results emerge from our model. First, a central bank's collateral policy plays an important role in determining the optimal interest rate corridor. In the absence of peer monitoring, we show that it is optimal to have a positive corridor if the opportunity cost of holding collateral is positive. To understand this finding, note that the lending facility makes assets eligible to be used as collateral more liquid, whereas collateral can be rather illiquid interest-bearing assets. The standing facility thus allows households/banks to indirectly hold additional liquidity if needed. When collateral is costless to hold, the central bank encourages holdings thereof by decreasing the cost of transforming it into cash. Increasing the wedge between the lending rate and the deposit rate increases this cost. Hence, when holding collateral is costless, the central bank should set a zero corridor, in which case households' consumption is financed only through collateral. In contrast, when holding collateral is costly, the central bank trades off the cost of holding cash over a period of time, the cost of holding collateral and the consumption flow from borrowing through the facility. By modifying the liquidity properties of collateral, monetary policy affects the portfolio decisions of households/banks and, as a consequence, the real allocation in the economy.

\section{A second aspect of the corridor system is that a central} bank can tighten its policy without changing its target rate. This is done by increasing the corridor symmetrically around the target rate, thus making it less attractive for banks to access the standing facility. As a result, when the recourse to a borrowing facility is the only option to obtain liquidity, the policy regime is tighter. This suggests that, for the same target rate, the 200 basis point corridors of the ECB and the Bank of England might imply tighter monetary policy than the 50 basis point corridor of the Reserve Bank of New Zealand.

Finally, in our model, the money market rate tends to be above the target rate if there is too little aggregate liquidity or if the opportunity cost of holding collateral is positive. This property of the model provides a contribution to the discussion on why the EONIA tends to be above the target rate (see Chart 1). The model suggests that the collateral requirements may impose additional costs on market participants.

Our model therefore complements Poole's findings in a dynamic general equilibrium set-up. Moreover, it lends itself to further extensions that can capture more elements of actual monetary policy implementation. For example, it would be interesting to add aggregate liquidity shocks and to endogenise the cost of holding collateral. However, the ultimate test will be to apply the model to the data and to replicate the behaviour of the money market rate. These are all possible avenues for future research.

\section{Box:The Wim Duisenberg Research Fellowship Programme}

In 2006 the ECB for the first time awarded the newly created Wim Duisenberg Research Fellowship, named after the ECB's first President, who died in 2005. The Wim Duisenberg Research Fellows are internationally renowned experts who are selected to visit the ECB for a period of between 3 and 11 months. The ECB funds one fellowship per year, which may be divided among several candidates.

The purpose of this fellowship programme is threefold. It aims to promote policy-relevant research that meets the highest academic standards. It offers research staff at the ECB the opportunity to gain exposure to and experience in the most recent advances in economic research. It gives prominent scholars the opportunity to gain an insight into the policy-making environment of the ECB.

Two people were selected for the 2006 fellowship programme: Albert Marcet and Philippe Weil. Albert Marcet visited the ECB during the summer and worked on the introduction of learning into rational expectation models, 
which helps to explain excessive stock market volatility. He has published widely in top academic journals, such as the American Economic Review, the Review of Economic Studies, the Journal of Political Economy and the Journal of Monetary Economics. He is currently affiliated with the Centre de Recerca en Economia Internacional at the Universitat Pompeu Fabra in Barcelona.

Philippe Weil is visiting the ECB for three months from October to December 2006. He is exploring the interdependence of labour market and credit market frictions and their joint effect on unemployment. The relative tightness of labour and financial markets could give rise to very different transmission effects of the credit channel of monetary policy. Philippe Weil has also published widely in top journals, such as the American Economic Review, the Quarterly Journal of Economics, the Review of Economic Studies, the Journal of Monetary Economics and Econometrica. He is currently a professor at the Université Libre de Bruxelles.

The Wim Duisenberg Research Fellows for 2007 will be the following: Bruno Biais from Toulouse University will analyse the European corporate bond market. Michael Burda from the Humboldt University Berlin will study household time use. Alex Cukiermann from Princeton University will conduct research on the limits of central bank transparency. Paul De Grauwe from Leuven University will examine the foundations of DSGE models. The 2007 fellows will be introduced in greater detail in the next Research Bulletin.

The call for applications for 2008 will shortly be posted on the ECB's website. Further information on this programme can be obtained from Lucrezia Reichlin, Director General Research at the ECB, at Lucrezia.Reichlin@ecb.int.

\section{References on "Central bank communication"}

Bank of England (2005), "Do financial markets react to Bank of England communication?", Quarterly Bulletin, Winter 2005, pp. 431-39.

BIS (2004), 74th Annual Report.

Brand, C., D. Buncic and J. Turunen (2006), "The impact of ECB monetary policy decisions and communication on the yield curve", ECB Working Paper No 657.

Demiralp, S. (2001), "Monetary policy in a changing world: Rising role of expectations and the anticipation effect", Board of Governors Finance and Economics Discussion Paper, pp. 2001-55.

Demiralp, S. and O. Jorda (2002), "The announcement effect: Evidence from open market desk data", Federal Reserve Bank of New York Economic Policy Review 8, pp. 29-48.

Diron, M. and B. Mojon (2005), "Forecasting the central bank's inflation objective is a good rule of thumb", $E C B$ Working Paper No 564.

Ehrmann, M. and M. Fratzscher (2005), “Transparency, disclosure and the Federal Reserve”, ECB Working Paper No 457, forthcoming, International Journal of Central Banking.

Ehrmann, M. and M. Fratzscher (2006), "Communication and decision-making by central bank committees: Different strategies, same effectiveness?", forthcoming, Journal of Money, Credit and Banking.

Fatas, A., I. Mihov and A. Rose (2006), "Quantitative goals for monetary policy, forthcoming", Journal of Money, Credit and Banking.

Gürkaynak, R., A. Levin and E. Swanson (2006), "Does inflation targeting anchor long-run inflation expectations? Evidence from long-term bond yields in the US, UK and Sweden", Federal Reserve Bank of San Francisco Working Paper No 2006-09.

Gürkaynak, R., B. Sack and E. Swanson (2005), "Do actions speak louder than words? The response of asset prices to monetary policy actions and statements", International Journal of Central Banking, 1, pp. 55-94.

Lange, J., B. Sack and W. Whitesell (2003), "Anticipation of monetary policy in financial markets", Journal of Money, Credit and Banking 35 (6), pp. 889-909.

Levin, A. T., F. M. Natalucci and J. M. Piger (2004), "Explicit inflation objectives and macroeconomic outcomes", ECB Working Paper No 383.

Poole, W. and R. H. Rasche (2003), "The impact of changes in FOMC disclosure practices on the transparency of monetary policy: Are markets and the FOMC better 'Synched'?”, Federal Reserve Bank of St. Louis Review January/ February, pp. 1-10.

Reinhart, V. and B. Sack (2006), "Grading the federal open market committee's communications", paper presented at the 2006 AEA meetings, Boston. 
References on "A Real-Time DataBase for the euro area"

Coenen, G., A. Levin and V. Wieland (2005), "Data uncertainty and the role of money as an information variable for monetary policy”, European Economic Review, 49(4), pp. 975-1006.

Giannone, G., J. Henry, M. Lalik and M. Modugno (2006), "An area-wide Real-Time DataBase for the euro area", ECB Working Paper series, forthcoming.

\section{References on "Implementing monetary policy using a corridor system"}

Berentsen, A. and C. Monnet (2006), "Monetary policy in a channel system", manuscript, ECB.

Bindseil, U. (2004), "Monetary policy implementation, theory, past and present", Oxford University Press.

Ewerhart, C., N. Cassola, S. Ejerskov and N. Valla (2004), "Liquidity, information, and the overnight rate", ECB Working Paper No 378.

Gaspar, V., G. Perez-Quiros and H. Rodriguez-Mendizabal (2004), "Interest rate determination in the interbank market", ECB Working Paper No 351.

Hartmann, P., M. Manna and A. Manzanares (2001), "The microstructure of the euro money market”, Journal of International Money and Finance, 20(6), pp. 895-948.

Nyborg, K. W., U. Bindseil and I. A. Strebulaev (2002), "Bidding and performance in repo auctions: evidence from ECB open market operations", ECB Working Paper No 157.

Poole, W. (1968), "Commercial bank reserve management in a stochastic model: implications for monetary policy", Journal of Finance, 23, pp. 769-91.

Whitesell, W. (2006), "Interest rate corridors and reserves", Journal of Monetary Economics, 53, pp. 1177-95.

\section{Selected recent journal publications by ECB staff}

Altissimo, F., L. Bilke, A. Levin, T. Mathä and B. Mojon (2006), "Sectoral and aggregate inflation dynamics in the euro area”, Journal of the European Economic Association, 4(2-3), pp. 585-593.

Álvarez L., E. Dhyne, M. Hoeberichts, C. Kwapil, H. Le Bihan, P. Lünnemann, F. Martins, R. Sabbatini, H. Stahl, P. Vermeulen and J. Vilmunen (2006), "Sticky prices in the euro area: a summary of new micro evidence”, Journal of the European Economic Association, 4, pp. 575-584.

Angeloni, I., L. Aucremanne and M. Ciccarelli (2006), “Price setting and inflation persistence: did EMU matter?”, Economic Policy, 21(42), pp. 354-387.

Angeloni, I., L. Aucremanne, M. Ehrmann, J. Galí, A. Levin and F. Smets (2006), "New evidence on inflation persistence and price stickiness in the euro area: implications for macro modelling”, Journal of the European Economic Association, 4(2-3), pp. 562-574.

Ciccarelli, M. and A. Rebucci (2006), "Has the transmission mechanism of European monetary policy changed in the run-up to EMU?”, European Economic Review, 50(3), pp. 737-776.

De Walque, G., F. Smets and R. Wouters (2006), "Firm-specific production factors in a DSGE model with Taylor price setting”, International Journal of Central Banking, 2(3), September 2006, 107-154.

Druant, M., S. Fabiani, I. Hernando, C. Kwapil, B. Landau, C. Loupias, F. Martins, T. Mathä, R. Sabbatini, H. Stahl and A. C. J. Stokman (2006), "What firms' surveys tell us about price-setting behaviour in the euro area”, International Journal of Central Banking, 2(3), pp. 3-46.

Gaspar, V., F. Smets and D. Vestin (2006), “Adaptive learning, persistence, and optimal monetary policy”, Journal of the European Economic Association, 4(2-3), 376-385.

Giannone, D. and L. Reichlin (2006), “Does information help recovering shocks from past observations?”, Journal of the European Economic Association, 4(2-3), pp. 455-465.

Giannone, D., L. Reichlin and L. Sala (2006), "VAR's, common factors and the empirical validation of equilibrium business cycle models”, Journal of Econometrics, 132(1), pp. 257-279.

Lombardo, G. (2006), "Inflation targeting rules and welfare in an asymmetric currency area”, Journal of International Economics, 68, pp. 424-442.

Tapking, J. (2006), “Multiple equilibrium overnight rates in a dynamic interbank market game”, Games and Economic Behaviour, 56(2), pp. 350-370.

Vestin, D. (2006), “Price-level versus inflation targeting”, Journal of Monetary Economics, 53(7). 